\title{
Ensino-aprendizagem de FLE: proposta de análise sobre o emprego das TICE em um livro didático
}

Ezequiel Bezerra Izaias de Macedo ${ }^{1}$

Joice Armani Galli ${ }^{2}$

Resumo: Este trabalho tem por objetivo realizar uma análise da utilização das novas tecnologias em um manual de francês. Para tanto, fazemos uso das teorias de Christian Puren $(1998,2001)$ sobre a evolução do ensino do Francês Língua Estrangeira (FLE) e o emprego das Tecnologias de Informação e Comunicação no Ensino (TICE). Vamos nos apoiar no Cadre Européen Commun de Référence pour les Langues (CECR, 2005) como também no Guide pour la recherche en didactique des langues et des cultures: approches contextualisées (2011), organizado por Philippe Blanchet e Patrick Chardenet. A partir dos pressupostos de VendelhanBourgade (2007) e de acordo com os postulados de Bertocchini e Constanzo (2008), a metodologia utilizada vai valer-se de uma análise qualitativa do livro didático Écho Al (2010). A presente pesquisa propõe investigar as marcas das TICE no ensino-aprendizagem do FLE, procurando mostrar como o referido manual as utiliza, favorecendo assim que se desenvolvam tanto a criatividade quanto a autonomia no processo pedagógico de aquisição do FLE.

Palavras-chave: FLE. TICE. Livro didático.

\section{À propos de l'enseignement et de l'apprentissage du FLE: proposition d'analyse de l'emploie des TICE dans un manuel}

\footnotetext{
${ }^{1}$ Professor de Francês. Graduado em Letras pela UFPE, atualmente realiza o curso de Mestrado Acadêmico em Linguística nesta Instituição. E-mail: e.bim@hotmail.com.

${ }^{2}$ Professora de Francês, Mestre em Teoria da Literatura e Doutora em Linguística Aplicada. Atualmente é Coordenadora do curso de Graduação de Letras-Francês da UFPE e docente do Programa de PósGraduação em Letras desta Instituição. E-mail: armani.galli@ via-rs.net.
} 
Résumé : Ce travail a comme but la réalisation d'une analyse de nouvelles technologies dans un manuel de français. Pour ce faire, nous utilisons les théories de Christian Puren $(1998,2001)$ en ce qui concerne l'évolution de l'enseignement du Français Langue Etrangère (FLE) et l'emploi des Technologies de l'information et de la communication pour l'enseignement (TICE). Nous nous pencherons sur le Cadre européen commun de référence pour les langues (CECR, 2005) et également sur le Guide pour la recherche en didactique des langues et des cultures : approches contextualisées (2011), dont les responsables du recueil sont Philippe Blanchet et Patrick Chardenet. À partir des pressuposés de Vendelhan-Bourgade (2007) et les postulats de Bertocchini et Constanzo (2008) la méthodologie de la recherche est tournée vers l'analyse qualitative de la première parution du livre Écho Al (2010). Notre étude propose la description du recours aux nouvelles technologies dans l'enseignement-apprentissage du FLE, afin de montrer la façon dont ce manuel les utilise favorisant l'esprit créatif et de l'autonomie des étudiants tout au long de la démarche pédagogique d'acquisition du français.

Mots-clés: FLE. TICE. Manuel didactique.

\section{Introdução}

Nos dias atuais, desfrutamos de um mundo cada vez mais conectado. A partir do momento em que dominamos uma ou mais línguas estrangeiras (LE), podemos nos tornar sujeitos mais ativos nesse universo plurifacetado. O processo de globalização traz informações sobre diversos assuntos, de forma quase instantânea. É interessante prestar atenção às nuanças das LE, com a finalidade de melhorar nosso processo de interação pessoal. Nesse contexto, aparece a língua francesa:

Do ponto de vista geopolítico, o Francês continua sendo a segunda língua do mundo. Mais de 250 milhões de pessoas falam Francês hoje como língua materna ou segunda língua. Cinquenta e um estados, dos quais 25 países o têm como língua oficial. Em 52 países o Francês é a língua da administração, do ensino, da mídia, do comércio, dos negócios ou do exército. A França tem o terceiro cinema do mundo e é um dos primeiros países do mundo em termos de livros publicados por habitantes (GERALDINI, 2007, p. 9).

Como vimos, urge que nos comuniquemos de uma maneira clara, para que possamos desempenhar bem nosso papel na comunidade em que vivemos. Utilizar 
adequadamente a língua é condição desejável para desfrutarmos de uma melhor qualidade de vida e de uma maior inserção cultural. Isso é justamente o que propõe

Galli (2011, p. 15), afirmando que "Perspectivar o ensino de LE de forma inclusiva deve ser política dos sistemas públicos de educação". Assim, as pessoas podem ir mais longe, passando a cultivar e exigir seus direitos assumindo, portanto, sua cidadania.

A respeito da importância do ensino de LE, a autora comenta ainda, na esfera pública, que:

Sob o prisma do que seja ensinar LE neste contexto, somam-se, às resistências e dificuldades, outros fatores como o imaginário coletivo no tocante ao ensino de LE, o qual ainda vislumbra, no ensino deste campo do saber, um caráter imediato, para fins específicos, tais como viagens, concursos, ingresso aos programas de pós-graduação (GALLI, 2011, p. 17).

O pensamento supracitado põe em relevo o dinamismo de uma língua como ferramenta para promover a autonomia do sujeito aprendiz, não restringindo somente para o emprego utilitário da aquisição de uma LE. Voltemo-nos, então, para a aprendizagem do Francês Língua Estrangeira (FLE), na qual está centrada a nossa pesquisa. Queremos afirmar, de início, que a metodologia de ensino de uma LE, por seu caráter dinâmico, pode e deve modernizar-se sempre. Para tanto, professores e alunos precisam fazer uso das novas tecnologias disponíveis na rotina diária, condição imprescindível para o aperfeiçoamento, nos contextos escolares do século XXI.

Nesse sentido, entendemos que é necessário tornar-se letrado, apropriando-se dos usos e das funções sociais da fala e da escrita. Concordamos com Xavier (2005, p.

133), ao afirmar que "Sem dúvida, a escola, com o auxílio dos meios de comunicação tradicionais (rádio, TV, jornais, revistas etc.) e agora modernos (Internet, CD, CD-ROM,

DVD), ajuda a consolidar a cultura da escrita". Assim, é fundamental ir além dos ensinamentos da escola, servindo-se das diversas agências de letramento disponíveis na sociedade, tais como a família, a igreja, a mídia, etc.

Há muito tempo dispomos das Tecnologias para a Informação e Comunicação no Ensino (TICE) para melhorar o nível de aprendizagem do FLE. O desabrochar dessas 
tecnologias aconteceu junto com o final da Segunda Guerra Mundial, quando o mundo conheceu o rádio. Em 1950, surgiu a televisão. Mas a necessidade de armazenar informações de maneira descentralizada, bem como de distribuí-las de modo rápido e eficiente fez as pesquisas evoluírem. Apareceu, vinte anos mais tarde, o computador, que ofereceu novos modos de pensar e escrever.

Dentre os diversos acontecimentos tecnológicos assistimos, nos anos de 1980, à chegada do projetor de imagens e, dez anos mais tarde, ao desembarque da multimídia no ensino. Nos dias de hoje, desfrutamos igualmente da internet que, com as redes sociais, os blogs, vlogs e outros recursos, desempenham um papel realmente destacado na aprendizagem e na consolidação de uma LE.

Com o passar do tempo, alguns objetos vão ter outras destinações diferentes, observação que se aplica ao rádio, o qual não tendo sido inventado com fins pedagógicos é, no entanto, utilizado atualmente nas escolas. Outro exemplo é a televisão, que auxilia no aprimoramento do percurso educacional e serve como instrumento considerável no sentido de aumentar a autonomia do sujeito aprendiz de FLE. Da mesma forma, acontece com outros utensílios, tais como os tablets e os aparelhos celulares, uma vez que fornecem elementos para a criatividade do usuário, trazendo ganho de tempo e diminuindo distâncias na aprendizagem de línguas.

\section{O ensino-aprendizagem do FLE}

A busca por uma LE deve estar presente na formação de todo sujeito. Ao longo dos anos, a língua francesa vem se colocando progressivamente como uma alternativa de aprendizagem de LE, não somente no Brasil, bem como no mundo. Em tempos mais antigos, o aprendizado se baseava na estrutura das línguas clássicas, tais como o latim e o grego. Nesse sentido, a Metodologia Tradicional (MT) ${ }^{\mathbf{1}}$ sempre foi requisitada, por valorizar a gramática: “Trata-se dessa metodologia herdada do ensino de línguas antigas 
(latim e grego), baseada no método conhecido como 'gramática/tradução' e em emprego corrente no ensino secundário francês até a imposição oficial da metodologia direta em 1902" (PUREN, 1988, p. 23) ${ }^{3}$.

Vale ressaltar que traços dessa metodologia ainda podem ser vistos. Porém, é preciso ter em mente a necessidade de contextualizar o ensino. Atentando para isso, o professor oferecerá melhores condições de aprendizagem a um aluno que deve ser ativo na busca pelo conhecimento, princípios pressupostos pela Abordagem Contextualizada, como se verá posteriormente.

Em princípios do século XX a Metodologia Direta (MD) foi imposta no ensino secundário, sendo introduzida por intermédio de instruções oficiais do governo francês, como uma oposição sistemática à MT. Sem passar pelo intermédio da língua materna, buscava possibilitar que o aluno se exprimisse de forma direta na LE, fazendo uso da expressão oral (EO).

Ainda na primeira metade do século XX surge a Metodologia Ativa (MA) que, procurando equilibrar as escolas anteriores, introduz novos elementos, os quais darão mais agilidade ao ensino. Veja-se, por exemplo, a prática do trabalho em grupo, que trouxe a figura do monitor, o qual tem um papel fundamental como facilitador da aprendizagem. Valoriza, então, a cultura, integrando-a ao processo pedagógico. $\mathrm{O}$ aluno compara e interpreta o conteúdo, desenvolvendo as habilidades de compreensão escrita (CE) e expressão escrita (EE).

O surgimento das TICE faz emergir a Metodologia Audiovisual (MAV), que pode assim ser definida: “[...] como a metodologia dominante na França nos anos 1960 e 1970, cuja coerência é baseada na utilização conjunta da imagem e do som”4. (PUREN, 1988, p. 284)

\footnotetext{
${ }^{3}$ Essa citação bem como todas as demais cuja fonte da escrita é a língua francesa, serão traduzidas por nós, reservando para a nota de rodapé a versão original, conforme segue: Il s'agira de cette méthodologie héritée de l'enseignement des langues anciennes (latin et grec), basée sur la méthode dite de « grammaire/traduction » et en usage général dans 1'Enseignement secondaire français jusqu à l'imposition officielle de la méthodologie directe en 1902 (PUREN, 1988, p. 23).

4 “[...] comme cette méthodologie dominante en France dans les années 1960 et 1970, et dont la cohérence est construite autour de l'utilisation conjointe de l'image et du son" (PUREN, 1988, p. 284).
} 
O suporte audiovisual vai dominar nesse período valendo-se de um feito inédito, utilizando ao mesmo tempo imagem e som. As principais ações da MAV são desenvolvidas por exercícios de combinação. O estudante realiza atividades de reprodução e de expressão, as quais desenvolvem as habilidades de Compreensão Oral (CO) e Expressão Oral (EO).

Um fato relevante é a ruptura epistemológica que vai aparecer a partir do momento em que se passa a empregar o vocábulo "abordagem" e não mais "metodologia". Puren (1988, p. 386) postula que o termo abordagem corresponde a métodos diversificados, em função de elementos externos aos aprendizes, tais como: diferentes objetivos, conteúdos, tipos de suportes empregados, etc.

Nesse período, observa-se o desenvolvimento de várias correntes linguísticas como as teorias da enunciação, a análise do discurso e a socioliguística, dentre outras, as quais encontram eco na Abordagem Comunicativa (AC) nos estudos de LE. Visando atender particularmente adultos e migrantes, a AC caracteriza-se por um público heterogêneo, composto pelas mais variadas profissões. A comunicação é situada na base da aprendizagem e os interlocutores negociam os conteúdos que serão estudados. A recorrência ao recurso real do ato comunicativo, através dos documents authentiques insere o aprendiz em um contexto verossímil para a aquisição de LE.

Considerando-se, então, que a língua francesa perdia espaço, surgem outras modalidades como o Francês Instrumental (FI) ${ }^{5}$, desenvolvido para compensar a importância atribuída ao inglês, após a Segunda Guerra Mundial. O FI foi particularmente usado na América do Sul e no Brasil, sobretudo para os níveis de mestrado e doutorado. O público necessitava ler textos acadêmicos e contextualizá-los no campo das ciências, econômico ou em outras áreas de atuação, desenvolvendo prioritariamente a habilidade de CE.

Em meados dos anos 1990 passamos a conviver com uma nova forma de ensino do FLE chamada Abordagem Acional (AA). Assim, os alunos são chamados a cumprir

\footnotetext{
${ }^{5}$ Para mais informações sobre o FI, sugere-se a leitura do artigo A leitura sociointerativa no curso de Letras Francês da UFPE, (GALLI, 2014), conforme consta nas referências.
} 
"tarefas", como verdadeiros atores sociais. Os actes de parole, surgidos ainda na escola anterior (AC) demandam ideias, sentimentos e emoções, preconizando que não existe discurso neutro. Essa abordagem, dando continuidade a um aspecto iniciado pela AC, utiliza também documentos autênticos, procurando concretizar projetos ao convidar l'apprenant, como passa a ser nominado o aprendente, a interagir em sala de aula. Aliás, consideramos tal terminologia mais adequada por explicitar a diferença técnica do termo aprendiz para a indicação de processo sugerida por aprendente.

No início da década são implantados estudos para um projeto grandioso que foi o Cadre Européen Commun de Référence pour les Langues (CECR, 2005). Esse documento direcionou o ensino LE por meio de parâmetros, que incluem a Competência Intercultural (CI), ao lado das demais habilidades linguísticas (CE/EE, CO/EO), indicando diversidade e pluralidade, características próprias da francofonia. O "Cadre", como é chamado, serve de guia para classificação dos livros didáticos. Assim, estamos de acordo com Coimet, $(2014, \text { s/n })^{6}$, quando afirma que o termo francofonia designa um “[...] espaço de confluências linguísticas e culturais em que os falantes compartilham a língua francesa

[...] é a concepção do francês compartilhado, que leva em conta a comunidade francófona multilíngue e cultural".

Ainda por esse período surge a Abordagem Sociodidática (AS), preconizada pelo Guide pour la recherche en didactique des langues et des cultures: approches contextualisées (BLANCHET; CHARDENET, 2011), que põe em relevo a internet, consagrando o papel das TICE na história das metodologias. Nesse sentido, é preciso não somente que se apreenda o contexto de atuação, mas que se compreenda a expectativa do público em termos de aprendizagem. Sob tal perspectiva será analisado a seguir o livro didático Écho Al (2010).

\section{O Écho A1}

\footnotetext{
${ }^{6}$ A este respeito, sugere-se a leitura do Numéro Spécial "Francophonie 2013/2014 - Édition Bilingue" da Revista Ao Pé da Letra, conforme consta nas referências.
} 
O manual de ensino de francês Écho Al (2010) destina-se a adultos e adolescentes que se iniciam na língua. É apropriado também aos faux débutants como, por exemplo, aos estudantes que, de alguma forma, já tiveram contato com o idioma francês, sem necessariamente se aprofundarem no seu estudo.

O conjunto didático compõe-se de um livro, de um caderno de atividades, de um CD-ROM e de um portfólio. Ressalte-se que, a partir de julho de 2013, a editora passou a oferecer também o livro digital, através de sua $2^{\mathrm{a}}$ edição. Dessa forma, os conteúdos do manual estão disponíveis na internet, trazendo assim mais uma opção para o usuário e maximizando a relevância das TICE como recurso didático-tecnológico. Porém, assinalamos que a presente análise é referente à primeira edição, lançada três anos antes.

É de se notar o caráter multimodal do Écho Al (2010):

“[...] a Multimídia, promotora da confluência de vários meios de comunicação centralizados no computador, proporcionou o acesso a um enorme volume de dados, transformando o quotidiano de seus usuários em um oceano de textos, ícones, imagens e sons plurissignificativos" (XAVIER, 2002, p. 8).

Entendemos linguagem multimodal como aquela que integra som, imagem, texto e animação, o que pode ser encontrado no manual em tela. A multimodalidade apresenta muitas vantagens para o ambiente educativo e colabora com o processo de ensinoaprendizagem.

Perspectivado pela AA, o manual põe em destaque o aprendente. Dessa maneira, o estudante se encaixa em um mundo no qual a cultura francesa preenche o ambiente de aprendizagem desde o princípio. Na introdução do livro Écho Al (2010) é dito que, desde a primeira hora de aula, o usuário pode ser considerado como um ator: "A aula torna-se então um espaço social no qual se trocam informações, experiências, opiniões e onde serão 
construídos projetos" (EA1, p. II) ${ }^{7}$. Nesse cenário nascem as interações entre os diversos sujeitos dos discursos, como também a vontade de conhecer e dominar as competências da LE.

A proposta do manual é de uma sucessão de três unidades, cada uma representando entre 30 e 40 horas de aprendizagem, que são assim divididas:

a) Duas páginas intituladas Interactions, nas quais o aluno encontra documentos que permitem colher informações ou mesmo se exprimir no quadro social proposto. Possibilitam introduzir os elementos lexicais e gramaticais que posteriormente facilitarão os trabalhos a serem desenvolvidos.

b) Duas páginas que se chamam Ressources, nas quais para cada ponto importante da língua será proposto um percurso que vai desde a observação até a sistematização. Nessa sessão o aluno se depara com vários textos, os quais servem para treinar a aquisição das diversas competências a que se refere o CECR (2005).

c) Duas páginas designadas como Simulations, nas quais o aprendente vai encontrar diálogos que contêm elementos linguísticos estudados anteriormente, os quais se juntam para contar uma história.

d) Uma página chamada Écrits, na qual são propostos diferentes textos aos estudantes, no intuito de que eles possam adquirir as estratégias de CE e de EE.

e) Uma página que se denomina Civilisation, na qual o aprendiz poderá aumentar sua visão sobre os temas cultura, civilização e cidadania. São textos amparados em linguagem multimodal, trazendo diversas representações de cores, de números e de letras, que ajudam na compreensão do universo francófono.

No final de cada unidade, são apresentadas as seguintes partes:

f) Quatro páginas designadas Bilan, nas quais o aluno tem a possibilidade de verificar suas competências, fazendo uma prestação de contas do que estudou.

\footnotetext{
7 "La classe devient alors un espace social où s'échangent des informations, des expériences, des opinions et où vont se construire des projets" (EA1, p. II) Doravante abreviaremos as páginas do manual Écho Al (2010) da seguinte forma: (EA1, p....).
} 
de

g) Três páginas nomeadas Évasion, previstas para possibilitar a oportunidade

sair do manual, trazendo geralmente propostas de passeios voltados para o mundo social, histórico e cultural francófono. Será sobre tais propostas que se pretende desenvolver o presente trabalho.

\section{A relação TICE/FLE/Livro didático}

Ao analisarmos o referido livro didático, sustentaremos o estudo no artigo sobre categorização de manuais, assinado por Vendelhan-Bourgade (2007) e que compõe o Guide pour la recherche en didactique des langues et des cultures: approches contextualisées (2011). Buscaremos suporte também nos postulados de Bertocchini e Constanzo (2008), autoras que apresentam, igualmente, uma proposta de grade para análise de manuais.

Inicialmente, segundo Vendelhan-Bourgade (2007), temos a orientação de dividir o manual em duas grandes áreas, que são chamadas “Os domínios da análise” e

"O olhar do pesquisador". Na primeira divisão são propostos os seguintes itens: 1. Condições de produção; 2. Objeto de estudo; 3. Conteúdo metodológico; 4. Conteúdo linguístico e 5. Concepção da ação pedagógica. Na segunda parte, temos: 1. Objetivos da pesquisa e procedimento adotado e 2 . O papel do ponto de vista.

Deve-se partir, assim, de uma conduta própria do pesquisador, que se traduz em um modo de análise, o qual vai ser observado sobre determinado ponto de vista e inserido em um domínio específico. Existem, portanto, inúmeras maneiras de se analisar um manual, as quais nos auxiliam a organizar as ideias, mas não esgotam as possibilidades analíticas.

Sobre as grades de análise de um manual didático, temos a proposta de Bertocchini e Constanzo (2008, p. 233-236). Nesse estudo, as autoras abordam a análise através de cinco itens: A. Apresentação global; B. Documentos e suportes; C. Conteúdos linguísticos e comunicativos; D. Língua e cultura: civilizações e E. Avaliação.

Os aspectos que nos interessam na análise dos dados do Écho Al (2010) estão contidos nas letras B, C e D citadas. Procuramos, sobretudo, analisar os textos verbais e 
não-verbais, bem como seus respectivos suportes. Verificamos seus conteúdos comunicativos, assim também a influência das civilizações francesa e francófona nas atividades de aprendizagem do FLE.

Iniciamos, assim, a análise do referido manual, segundo as ideias supracitadas, buscando uma visão historicamente situada do mesmo, como sendo de uma geração de manuais produzidos na primeira década do século XXI. Lançado no Brasil em setembro de 2010, durante uma jornada pedagógica, foi inicialmente concebido para responder à demanda do contexto específico institucional francês, particularmente no que se refere ao emprego das $\mathrm{TICE}^{8}$.

Partimos de um ponto de vista sociolinguístico, o qual estuda a língua em seu uso real, levando em consideração as relações entre a estrutura da linguagem e os aspectos socioculturais da produção linguística. Interessa-nos a relação existente entre linguagem e cultura, a qual vai ser refletida na civilização e na língua. Nossa pesquisa se debruça sobre os três projetos propostos no final das três unidades do manual, quais sejam: Projet Sortie Virtuelle, Projet Poésie en Liberté e Projet Improvisation, respectivamente "Projeto

Passeio Virtual", "Projeto Poesia em Liberdade" e "Projeto

Improvisação".

Começando pelo Projet Sortie Virtuelle (EA1, p. 42), verifica-se que o mesmo faz referência às TICE. Aborda três ferramentas tecnológicas que devem estar presentes ao longo de um ano letivo escolar: a televisão, o rádio e a internet. Esses suportes podem ser trabalhados a partir do laboratório da escola.

Sobre a internet, o projeto convida a um percurso virtual: "Viajar com Internet. Programe seu navegador (por exemplo, "Google") e inicie seus projetos, utilizando-se de sítios francófonos (EA1, p. 42)" ${ }^{9}$. Tal sessão apresenta várias oportunidades para

\footnotetext{
${ }^{8}$ Para mais informações, sugere-se uma navegação no sítio da Clé International http://cleformation.com/journees/index.php?option=com_content\&view=article\&id=156\&Itemid=149, no item específico à promoção de jornadas pedagógicas.

9 "Voyager avec Internet. Programmez votre moteur de recherche (par exemple « Google ») pour une recherche de sites francophones” (EA1, p. 42)
} 
prosseguir nessa viagem pela rede mundial de computadores e encontrar pessoas, regiões, monumentos e traços da cultura da língua estudada. Como exemplos são indicados alguns museus, tais como o Musée du Louvre ou o Musée d'Orsay.

Na página 42 é apresentado um sítio internet, sendo feitas algumas perguntas sobre o mesmo: “1. Que representa esse sítio? 2. Sublinhe as palavras que você compreende. 3. Sobre que palavra se pode clicar para conhecer ... as horas de abertura e fechamento [...]" ${ }^{10}$. Além da perspectiva acional, percebe-se explicitamente a preocupação em trabalhar situações reais de uso da língua e a maneira como isso ocorre, a partir do processo interativo, capital para a aquisição do FLE.

Nesse sentido, como afirma Galli (2013), ao se realizar uma pesquisa contextualizada, como se pretende que seja esta, tem-se a possibilidade de estudar a língua francesa para além do seu código. O caráter plurilíngue e francófono do FLE desvela-se pouco a pouco, por intermédio da sua diversidade cultural e linguística, já que a língua é criação e não mera reprodução, complementa a autora. Isso nos remete ao emprego de recursos tecnológicos no ensino de LE e à busca pelo plurilinguismo através de palavras transparentes, [les mots transparents].

$\mathrm{O}$ acesso às informações em língua francesa é facilitado a partir do momento em que se conhecem ou ao menos haja uma sensibilização para o aprendizado de outros idiomas que são bastante falados ao redor do mundo. Várias palavras e expressões "se parecem" em algumas línguas, pois têm uma origem comum, o latim. É o caso do português, do francês, do espanhol, do italiano ou do romeno.

O inglês partilha diversos vocábulos com o francês, devido não só à proximidade geográfica, mas por conta de um passado de conquistas em territórios visados por esses dois países. Elas são as línguas oficiais de vários organismos mundiais como, a Organização das Nações Unidas (ONU) e a Federação Internacional de Futebol (FIFA).

\footnotetext{
10 “1. Que représente ce site? 2. Soulignez les mots que vous comprenez. 3. Sur quel mot cliquez vous pour connaître ... les heures d'ouverture et de fermeture $[\ldots]$ "
} 
O Projet Sortie Virtuelle abre espaço para o rádio e para a televisão:

Assistir à televisão ... Escutar o rádio. Com a TV5 você pode assistir à televisão em francês em todo o mundo. Na programação das emissoras francesa dos canais France 2, France 3, France 5. Você está interessado(a) por informações em francês? Assista France 24. Você também pode escutar a RFI (Radio França Internacional). Esta emissora propõe um jornal de informações em um francês de fácil acesso, por meio de expressões e palavras simples e descomplicadas. (EA1, p. 43) ${ }^{11}$

O rádio, a nosso ver, tem um lugar importante no aprendizado de LE. As grandes emissoras mundiais podem ser ouvidas em praticamente todos os continentes. A TV5 Monde (TV5) é exemplo de um instrumento televisivo a serviço da francofonia ao redor do globo. Ela é transmitida para todo o mundo e os seus conteúdos são voltados para a região que vai escutá-la. Por exemplo, a transmissão para o Brasil é veiculada por meio da programação preparada para a América Latina. Com isso a cultura francesa pode ser mais bem assimilada pela sociedade local.

Outra fonte de consulta é o programa Br@nché. Trata-se de uma emissão produzida pela TV Escola, que veicula reportagens contemporâneas da TV5, voltada para professores e estudantes de francês. Apresenta vídeos e fatos contemporâneos, tendo como foco as culturas de língua francesa e sua interação com a cultura brasileira.

Por fim, são listados alguns endereços eletrônicos de jornais como, por exemplo, Le Monde e Le Figaro. A sessão nos convida a descobrir a França em nosso país, lembrando que nas grandes cidades do mundo existe sempre uma Aliança Francesa, um Centro Cultural ou um Instituto Francês (EA1, p. 44).

Prosseguindo na análise do manual, vejamos o Projet Poésie en Liberté (EA1, p. 82), o qual faz um chamamento particular à poesia. Sabemos que a civilização francesa atribui significativa importância à literatura desde os tempos mais remotos, tendo

\footnotetext{
${ }^{11}$ Regarder la télévision ... Écouter la radio. Avec TV5 vous pouvez regarder la télévision en français partout dans le monde. Au programme des émissions des chaînes France 2, France 3, France 5. Vous êtes intéressé(e) par des informations en français ? Regardez France 24. Vous pouvez aussi écouter RFI (Radio France Internationale). Cette radio propose un journal d'informations en français facile (EA1, p. 43).
} 
produzido grandes poetas, tais como Pierre de Ronsard, Arthur Rimbaud, Charles Baudelaire e Victor Hugo, dentre outros. O projeto especifica seus objetivos:

\begin{abstract}
A poesia retorna. Cada cidade tem o seu café literário, suas oficinas de escrita e sua Primavera dos poetas. Eis aqui uma saída em busca da poesia das cidades. Leia. Escute a música das palavras. Em seguida escreva poemas sobre sua cidade, sua região, seu bairro, sua rua ou sua casa. (EA1, p. 82$)^{12}$
\end{abstract}

Nessa passagem fica clara a importância dada à poesia. A melodia das palavras, os sons das frases, tudo nos convida à escrita. Como exemplo, temos o texto do cantor francês Grand Corps Malade, que se chama Vu de ma fenêtre, o qual é bem contemporâneo e explora a realidade atual dos subúrbios das grandes cidades francesas. Ao mesmo tempo, o aluno pode s deliciar com dois poemas que aproximam o século passado e o atual. São eles Zoom de Paul Éluard, publicado em 1954 e Regards, escrito por Louis Calaferte, em 2002 (EA1, p. 82 e 83).

As marcas das TICE podem ser vistas no cartaz da 9 e Printemps des poètes, que traz o endereço eletrônico do evento na sua parte inferior, qual seja: www.printempsdespoetes.com. A sessão sugere o sítio www.pages.infinit.net/haïku, no qual se pode pesquisar sobre a poesia japonesa. Ao explorar o que a poesia pode trazer para o crescimento do estudante em termos de alicerce linguístico, podemos compreender esse evento, que se propõe a divulgar a poesia do mundo inteiro.

Por fim, vamos ao Projet Improvisation (EA1, p. 122), que aborda o teatro. Queremos reafirmar o caráter cultural da língua francesa e a vocação do povo para as artes. A magia de representar é vista, quando se aborda a finalidade do projeto: "As melhores cenas de teatro são frequentemente inspiradas por momentos da vida quotidiana" [Les meilleures scènes de comédie sont souvent inspirées par des moments da la vie cotidienne]

\footnotetext{
${ }^{12}$ La poésie revient. Chaque ville a son café littéraire, ses ateliers d'écriture et son Printemps de poètes. Voici une évasion dans la poésie des villes. Lisez. Écoutez la musique des mots. Mais aussi écrivez des poèmes sur votre ville, votre région, votre quartier, votre rue ou votre maison. (EA1, p. 82)
} 
(EA1, p. 122). A sessão faz um convite para que o aluno possa descobrir por si mesmo o prazer do teatro, partindo de situações do seu cotidiano. Dessa forma dá-se ao estudante a possibilidade de fazer pesquisas, as quais certamente passarão por uma das TICE, tais como o rádio, a televisão, a internet ou outra multimídia.

Esse projeto sugere diversas cenas, as quais são extraídas de algumas peças de teatro que visam inspirar o aluno a buscar sua própria criação. Como exemplos são apresentadas algumas obras do século $\mathrm{XX}$, as quais visam inspirar os alunos. Temos, assim, as seguintes: [Le cadeau] "O presente", que é interpretada na época de natal, explorando uma situação inusitada de se presentear algo que não é comum; [Les invités surprises] "Os convidados surpresa", que trata de um diálogo entre um casal sobre fatos cotidianos, mostrando três versões da vida real; e [La consultation chez le médecin] "A consulta médica", a qual põe em cena um médico do que engana seus pacientes (EA1, p.

122-124).

Ao longo dessa sessão de saída em busca da improvisação, verificamos diversas explicações sobre os textos a serem estudados e utilizados pelos alunos. A dedicação às artes, implementada pelo povo francês se faz presente, quando o projeto orienta ao estudante para que: "1. Leia a cena em voz alta com o seu vizinho(a). Pesquise os momentos interessantes e agradáveis. 2. Imagine, redija e interprete (a dois)/ «1. Lisez la scène à haute voix avec votre voisin(e). Recherchez les moments amusants. 2. Imaginez, rédigez et jouez (à deux) » (EA1, p. 122). Caso esse chamamento seja seguido de pesquisas na internet, por exemplo, a fim de melhorar detalhes de imagens e sons das cenas sugeridas, as mesmas potencializarão o produto final dos trabalhos. Ao utilizar as TICE como ferramenta ativa, o aluno pode aprender um pouco mais sobre os diversos autores e as condições de produção das respectivas obras. Ao instigar o

"apprenant", as TICE trazem à cena sua autonomia e criatividade, além de guiá-lo nesse verdadeiro universo em profusão que é a rede mundial de computadores.

\section{Considerações finais}


O fato de dispormos de uma rotina globalizada, podendo utilizar novas tecnologias a todo o momento, nos conduz a algumas considerações. As distâncias físicas se tornam menores e as possibilidades de desenvolver atividades que antes pareciam complexas, se ampliam atualmente. Na diversidade do dia a dia, aparece o aprendizado de LE, que pode nos levar mais longe no caminho do autoaperfeiçoamento. Ao vivenciarmos as atividades culturais de outro povo, podemos passar a valorizar mais a nossa própria cultura, comparando valores e aprendendo novas maneiras de ver o mundo. Isto pode ser otimizado caso o estudante utilize as TICE para aprofundar seus trabalhos escolares.

Nesse sentido, sugerimos o aprendizado do FLE como mais uma ferramenta de desenvolvimento pessoal e formação cidadã. $O$ francês é uma língua que tem uma vocação universal, é falada em todos os continentes e aporta uma larga bagagem cognitiva. Além do mais, as grandes cidades brasileiras dispõem de instituições, tais como a Organização Internacional da Francofonia (OIF) ${ }^{13}$, que são entidades credenciadas e se encarregam de difundir a cultura francófona aos cidadãos interessados em conhecê-la.

Nosso estudo comporta uma visão sobre o ensino do FLE, apresentando as principais metodologias e abordagens utilizadas ao longo dos tempos. Cada uma delas reflete as marcas do seu momento. Os conteúdos são trabalhados de acordo com características como: o professor, o período, a didática, o assunto estudado, o tempo disponível, as potencialidades dos alunos etc, os quais são fundamentais para o processo de ensino-aprendizagem do FLE porque situados histórica e socialmente. Buscamos descrever o manual Écho Al (2010), como sendo um livro multimodal, produzido recentemente e com apelo recorrente às TICE. Estes fatos contribuem para um ensino eficiente do FLE, a partir do momento em que o estudante se vê no centro do processo educativo. Ele pratica, ele sente, ele se emociona, ele vive, ele descobre as cores da língua, fazendo uso de um suporte metodológico moderno.

Logo no início da análise dos dados, ao nos debruçarmos sobre o Projet Sortie Virtuelle (EA1, p. 42), verificamos a expressiva recorrência do documento à utilização das TICE. O estudante é convidado a realizar uma viagem virtual, sendo chamado a

\footnotetext{
${ }^{13}$ Para mais informações, sugere-se uma visita ao sítio da OIF, conforme consta nas referências.
} 
experimentar a internet, o rádio e a televisão. São apresentados, assim, diversos endereços virtuais, nos quais o aluno pode trabalhar os principais aspectos da cultura francesa em torno do mundo, orientando-o para uma pesquisa seletiva e progressiva.

Ressaltamos que o estudante ouça o rádio e assista à televisão. O projeto em tela apresenta a RFI e a TV5, que podem ser acessados de qualquer lugar do planeta. São organizações do governo da França que apresentam uma programação educativa que visa ensinar a língua francesa de forma agradável e convidativa, levando as marcas da francofonia aos confins do globo.

Nesse caminho, plurilinguismo e francofonia sugerem sensibilização linguística. Por ser uma língua latina, consideramos que não seja tão difícil assim se lançar ao seu aprendizado, uma vez que há vários pontos que facilitam a sua apreensão, a exemplo das mots transparents, palavras transparentes, tais como os substantivos, os verbos e os adjetivos latinos. Além do mais, não é preciso muito para se perceber a presença da cultura francesa na formação intelectual brasileira, diferentemente de um domínio linguístico e cultural.

Continuando, passamos ao Projet Poésie en Liberté (EA1, p. 82), o qual põe em cena uma das atividades que o povo francês muito valoriza que é a escrita. Basta ver que a Academia Francesa de Letras serviu de inspiração para a nossa congênere pelo seu fundador, o escritor Machado de Assis. Nesse projeto, pode-se afirmar que as TICE se destacam, quando se alia o poder do mundo virtual ao dos livros. Através da internet, é possível conhecer mais sobre os autores e suas produções, incitando o processo investigativo.

Por último, analisamos a presença das TICE no Projet Improvisation (EA1, p. 122), que embora não seja tão direta, pode ser sentida, ao longo do texto. Esse projeto conduz o estudante a uma dimensão muito valorizada pelos franceses, que é a arte. O cinema e o teatro também são instrumentos efetivos de difusão da língua de Molière. A partir do momento em que o estudante agrega as possibilidades do computador à sua produção, utilizando programas digitais, redes sociais e pesquisas na internet, as TICE otimizarão o processo de aquisição da linguagem. 
Ao finalizarmos, registramos que parte percurso foi trilhada, mas muito há que caminhar. No que tange à língua francesa, trata-se de um instrumento que insere social, cultural e historicamente o usuário no mundo, como um todo. Postulamos, então, que o resultado do cruzamento entre TICE, FLE e livro didático multiplica os níveis de conhecimento e de autonomia do estudante, aprimorando sua aquisição de conhecimentos e desenvolvendo seu letramento digital em LE.

\section{Referências}

ALVES, A. P. Leitura em Francês Língua Estrangeira: relações entre manual didático e material complementar. Rio de Janeiro: UFRJ, 2011.

BERTOCCHINI, P ; COSTANZO, E. Manuel de Formation Pratique pour le professeur de FLE. Paris: Clé International, 2008.

BLANCHET, P ; CHARDENET, P. (Orgs). Guide pour la recherche en didactique des langues et des cultures : approches contextualisées. Paris: EAC, 2011.

CONSEIL DE L'EUROPE. Cadre européen commun de référence pour les langues : Apprendre. Enseigner, évaluer. Paris: Didier, 2005.

GALLI, J. A. A leitura sócio-interativa no curso Letras-Francês EAD da UFPE. Disponível em http://nehte.com.br/simposio/anais/simposio2013.html. V Simpósio Hipertexto. Recife, 2013. Acessado em 31 Mar 2014. 
GALLI, J. A. Letramento digital no ensino à distância de língua francesa na UFPE: identidades (in)visíveis. Recife, 2013. Disponível em http://www.issuu.com /neplev/docs/identidade_e_espaco_virtual. Acessado em 10 Dez 2013

GALLI, J. A (Org). Línguas que botam a boca no mundo: reflexões sobre teorias e práticas de línguas. Recife: Editora Universitária, 2011.

GERALDINI, A. F. S. et al. Francês Língua Estrangeira: Novas demandas, novas respostas. São Paulo: DVS, 2007.

GIRARDET, J. ; PECHEUR J. Écho A 1 - Méthode de français. Paris: Clé International, 2010.

MINISTÉRIO DA EDUCAÇÃO - TV ESCOLA. ProgramaBr@nché. Disponível em http://www.youtube. com/ watch?v=GCvMe2iJ5D8. Acessado em 10 Dez 2013.

ORGANIZAÇÃO INTERNACIONAL DA FRANCOFONIA. Disponível em http:// www.francophonie.org. Acessado em 28 Jul 2014.

NUMÉRO SPÉCIAL FRANCOPHONIE 2013/2014 - Édition Bilingue. Revista Ao Pé da Letra. Disponível em http://www.revistaaopedaletra.net/volumeespecialfrancofonia.html. Acessado em 17 Jul 2014.

PUREN, C. La didactique des langues face à l'innovation technologique. Paris: Université de Technologie de Compiègne, 2001.

PUREN, C. Historie des méthodologies de l'enseignement des langues. Paris: Clé International, 1988.

RADIO FRANÇA INTERNACIONAL. Disponível em http://www.rfi.fr. Acessado em 10 dez 2013.

TV5 MONDE. Disponível em http://www.tv5.org. Acessado em 10 Dez 2013.

XAVIER, A. C. S. Letramento Digital e Ensino. In: SANTOS, C. F.; MENDONÇA, M. (Orgs). Alfabetização e Letramento: conceitos e relações. Belo Horizonte: Autêntica, 2005. 
XAVIER, A. C. S. O hipertexto na sociedade de informação: a constituição do modo de enunciação digital. Campinas: IEL, 2002.

Recebido em 20 de setembro de 2014 Aceito para a publicação em 16 de dezembro de 2014 